Referencia para citar este artículo: Wachelke, J. (2018). Relações entre prioridades de valores de adolescentes e posições sociais de renda e escolaridade. Revista Latinoamericana de Ciencias Sociales, Niñez y Juventud, 16(2), 913-927. doi: https://doi.org/10.11600/1692715x.16218

\title{
Relações entre prioridades de valores de adolescentes e posições sociais de renda e escolaridade*
}

\author{
JOAO WACHELKE ${ }^{* *}$ \\ Universidade Federal de Uberlândia, Brasil.
}

\begin{abstract}
Artículo recibido en septiembre 22 de 2017; artículo aceptado en diciembre 11 de 2017 (Eds.)
\end{abstract}
- Resumo (analítico): a pesquisa, baseada na teoria funcionalista dos valores, caracterizou a importância concedida por adolescentes de diversas posições sociais aos valores, considerados como princípios-guia individuais. Os participantes foram 736 estudantes secundaristas (51,5\% mulheres, média de idade: 16 anos) de Uberlândia, Brasil, que responderam uma versão adaptada do Questionário de Valores Básicos (QVB) e forneceram informações familiares sobre renda e escolaridade. Os dados foram tratados a partir de estatística descritiva e análise das correspondências. Os resultados indicam consensos e maiores proporções de alta importância para alguns valores centrais, suprapessoais, interacionais e de realização, corroborando pesquisas anteriores. Foram observadas variações em valores normativos como religiosidade e tradição, cuja importância decresce à medida que aumentam renda e escolaridade. Essa relação é discutida em termos das funções motivadoras, conformistas e ideológicas da religião.

Palavras-chave: valores, adolescentes, classes econômicas, escolaridade (Tesauro Ciencias Sociais da Unesco).

\section{Relationships between adolescents' values priorities and social positions established by their income and family's education levels}

- Abstract (analytical): This study is based on a functionalist theory of values and characterizes the importance that adolescents from various social positions place on certain values that act as individual guiding principles in their lives. The participants were 736 secondary school students (51,5\% females with an average age of 16) from Uberlandia, Brazil who completed an adapted version of the Basic Values Survey (BVS) and provided information about their family's education levels and income. The data was analyzed using descriptive statistics and correspondence analysis. The results indicate that there is a general consensus and higher proportions of high importance given to some central, suprapersonal, interactive and promotion values, corroborating previous research. Variations in normative values such as religiosity and traditions were observed, with their importance decreasing as income and education level increase. This relationship is discussed in terms of the motivating, conforming and ideological functions of religion.

Key words: values, adolescente, economic classes, schooling (Unesco Social Science Thesaurus).

\footnotetext{
* Este artigo de pesquisa científica e tecnológica faz parte de projeto denominado Pesquisa de Percepções Sociais de Estudantes Uberlandenses-2013 (Perseu-2013), com apoio financeiro do Conselho Nacional de Desenvolvimento Científico e Tecnológico (CNPq) brasileiro. A coleta de dados da pesquisa foi iniciada em agosto e concluída em outubro de 2013. O projeto iniciou-se em março de 2013 e foi concluído em fevereiro de 2014. Grande área ciências sociais, área de conhecimento psicologia, sub-área psicologia social.

** Professor adjunto do Instituto de Psicologia da Universidade Federal de Uberlândia (UFU), Brasil. Doutor em Psicologia Social e da Personalidade pela Università degli studi di Padova (Itália). Orcid: 0000-0003-4364-8598. Índice H5: 17. Correio eletrônico: joao.wachelke@ufu.br
} 


\section{Relaciones entre prioridades de valores de adolescentes y posiciones sociales de ingreso económico y escolaridad familiar}

- Resumen (analítico): la investigación, basada en la teoría funcionalista de los valores, caracterizó la importancia concedida por adolescentes de diversas posiciones sociales a los valores, considerados como principios guía individuales. Los participantes fueron 736 estudiantes de secundaria (51,5\% mujeres, media de edad 16 años) de Uberlandia, Brasil, que respondieron una versión adaptada del Cuestionario de los Valores Básicos (CVB) e información familiar sobre ingreso económico y escolaridad. Los datos fueron tratados a partir de estadística descriptiva y análisis de las correspondencias. Los resultados indican consensos y mayores proporciones de alta importancia para algunos valores centrales, suprapersonales, interactivos y de realización, corroborando investigaciones anteriores. Se observaron variaciones en valores normativos como religiosidad y tradición, cuya importancia decrece a medida que aumentan ingreso económico y escolaridad. Esta relación se discute en términos de las funciones motivadoras, conformistas e ideológicas de la religión.

Palabras-clave: valores, adolescentes, clases económicas, escolaridad (Tesauro Ciencias Sociales de la Unesco).

\section{-1. Introdução. -2. Método. -3. Resultados. -4. Discussão. -5. Referências.}

\section{Introdução}

O presente estudo busca relacionar a avaliação da importância de valores, isto é, sua priorização, e as posições que as pessoas ocupam na estrutura social em termos de acesso a recursos econômicos e culturais. Para tanto, primeiramente especifico o marco teórico que escolhi para abordar os valores, para posteriormente fundamentar o problema de pesquisa interligando prioridades valorativas e posições sociais.

$\mathrm{Na}$ psicologia social, há algumas teorias sobre os valores, com aspectos complementares e concorrentes (por exemplo: Inglehart, 1977; Pereira, Camino, \& Costa, 2005; Schwartz, 1992). Este estudo orienta-se pelo conceito da teoria funcionalista dos valores (Gouveia, 2013), cujos principais conceitos são detalhados a seguir. De acordo com essa teoria, os valores são princípios-guia que orientam a conduta das pessoas. São metas abstratas que se aplicam diversas situações gerais, conceitos ou categorias que se referem a estados desejáveis de existência e a podem ter graus diferentes de importância, ou prioridade, para as pessoas (Gouveia, 2003, 2013; Gouveia, Fonsêca, Milfont, \& Fischer, 2011; Rokeach, 1973).

Os valores desempenham duas funções. A primeira é a função de guiar o comportamento humano, que diz respeito ao direcionamento das ações das pessoas para um de três tipos de orientação: ou para a ênfase na vida individual e seguindo metas que atendam a seu próprio eu, ou para o bem-estar da coletividade e agindo em prol dos grupos sociais a que pertencem, ou a valores necessários tanto para finalidades individuais quanto coletivas. Esses três tipos são as orientações pessoal, social e central (Gouveia, 2003; Gouveia et al., 2011).

A segunda função é expressar as necessidades humanas. Os valores representam cognitivamente necessidades potencialmente universais da espécie humana. Os valores ou representam necessidades mais imediatas, práticas e concretas, enfatizando a própria existência e suas condições —um motivador materialista-, ou necessidades mais abstratas e inespecíficas, desvinculadas da existência biológica e elementos materiais, um motivador idealista ou humanitário (Gouveia et al., 2011).

A combinação dos tipos de orientação e motivador permite identificar seis subfunções. A subfunção realização tem orientação pessoal e motivador materialista. Ela representa necessidades de autoestima e agrupa valores que prezam pela busca de objetivos materiais e pessoais, como poder, prestígio e status. A subfunção normativa também tem motivador materialista, mas orientação social. 
Ela preza o respeito a normas sociais e instituições, de modo a controlar os impulsos para atingir as necessidades das pessoas. Obediência, religiosidade e tradição são valores normativos. Por sua vez, a subfunção existência, de orientação central, serve de referência para as outras subfunções materialistas, pois é compatível com a ênfase na sociedade ou no indivíduo, estabelecendo suas pré-condições. Reúne valores como sobrevivência, estabilidade pessoal e saúde. A subfunção experimentação tem motivação idealista e orientação pessoal. Ela diz respeito à busca do prazer ou hedonismo, e inclui valores como prazer, emoção e sexualidade. A subfunção interativa tem orientação social e motivador materialista, e corresponde às necessidades afetivas, de amor, pertencimento e estabelecimento de relações interpessoais, com valores como afetividade, apoio social e convivência. Finalmente, a subfunção suprapessoal, central e idealista, atende às necessidades de conhecimento, estética e desenvolvimento do próprio potencial, desprendida de aspectos materiais. Alguns valores suprapessoais são beleza, conhecimento e maturidade (Gouveia, Milfont, Fischer, \& Coelho, 2009; Medeiros, Gouveia, Gusmão, Milfont, Fonseca, \& Aquino, 2012).

\section{Prioridade dos valores}

O estudo de Medeiros et al. (2012) apresentou alguns resultados sobre as médias de prioridades das subfunções junto a uma amostra agregada de mais de doze mil pessoas do estado da Paraíba. Os participantes tinham ampla variação de idade e escolaridade. De modo geral, os escores de existência tiveram as maiores pontuações de prioridades, seguidos pelos valores interativos, normativos e suprapessoais.

Por sua vez, Gouveia, Milfont, Vione e Santos (2015a) tiveram uma amostra de mais de cinco mil universitários de psicologia e pedagogia, consultados de 2002 a 2004. A maioria foi formada por mulheres e tinha até 30 anos. Novamente, a maior importância foi associada aos valores de existência, seguida pelas subfunções interativa e suprapessoal.

Gouveia, Vione, Milfont e Fischer (2015b) também compararam as respostas de priorização de valores de pessoas divididas em grupos etários, compondo uma amostra de mais de trinta e seis mil participantes de todo o Brasil. Os autores conseguiram identificar padrões de mudanças dos valores no ciclo de vida. Os valores suprapessoais e interacionais tendem a crescer de modo linear, apresentando importância menor no início da adolescência e maior na velhice, valorizando aspectos abstratos como necessidade de crescimento pessoal e relações sociais, primeiro na forma de parceiros amorosos e família, e por fim como amizades. Para os adolescentes de cerca de 16 anos há um aumento em comparação com o início da adolescência. Experimentação e existência tendem a crescer em importância durante a adolescência média em comparação com os anos iniciais do período, aumentando no decorrer da vida e regredindo a estágio anterior na velhice. A experimentação é explicada pela busca de sensações e novidades associados com a juventude. Quanto à existência, provavelmente a sobrevivência psicológica se torna mais evidente para os adolescentes, já que estão em processo de formação de identidade. Os valores normativos são inicialmente mais altos em importância no início da adolescência, depois tornam-se menos pertinentes no meio do período, e depois voltam a ser priorizados. Os adolescentes encontram-se em fase de desafio às normas e regras familiares à medida que convivem com a sociedade fora de casa, o que explicaria essa menor importância dos valores normativos. Já a subfunção realização tende a ser maior na adolescência, diminui na idade adulta jovem, e depois volta a aumentar. Para os adolescentes, realização relacionase com a definição do futuro no trabalho.

O que determinaria a maior ou menor priorização de valores pessoais? Conforme a hipótese da escassez de Inglehart (1977), as pessoas tendem a considerar mais importantes aquilo que lhes falta; portanto, costumam priorizar as metas ligadas ao que não possuem e às coisas de que precisam ou que gostariam de ter, conforme sua socialização na infância e adolescência. A teoria funcionalista é de certo modo compatível com a ideia de que objetivos escassos direcionam a priorização de valores, entendendo que a concessão de maior ou menor importância a valores pessoais pode ser entendida 
como um mecanismo adaptativo atrelado às motivações individuais em cada momento da vida (Gouveia et al., 2015b).

Assim, para adolescentes, seria importante avaliar os principais conflitos e desafios que se lhes impõem, para interpretar a lógica subjacente à priorização de valores. Como o estudo de mudança de valores de Gouveia et al. (2015b) sugere, a estruturação de uma trajetória escolar que culminará futuramente num desfecho de trabalho e que possibilitará a obtenção de remuneração provavelmente associa-se a maior importância de valores de existência e realização. As novas experiências sociais vividas por adolescentes, ao aumentar a gama de relações sociais para além do meio restrito da família, frequentemente significam maior priorização de valores de experimentação e redução na importância das normas familiares, na busca por autoafirmação e identidade psicológica. Do mesmo modo, essas novas experiências e também o aumento da rede de amizade e contatos e busca por relações amorosas pode propiciar aumento na importância de valores de interação social e suprapessoais.

\section{Posições sociais}

Após considerações gerais sobre priorização de valores de adolescentes, cabe ir além e perguntar: como seria a priorização de valores pessoais por parte de adolescentes de posições sociais diferentes? Para tratar dessa questão, devo esclarecer o que quero dizer com posição social. As pessoas têm capacidades diferentes de agir sobre sua realidade, determinadas pela quantidade e tipo de recursos que detêm e que em última análise, correspondem ao poder que possuem sobre a sociedade. Bourdieu (1986) refere-se a esses recursos pelo nome de capital. Bourdieu (1989) utiliza o conceito de capital como sinônimo de formas de poder, propriedades que são objeto de disputa entre as pessoas. Os tipos de capital —ou poder social— dizem respeito a objetos, posses, habilidades ou propriedades, concretas ou intangíveis que são mais ou menos valiosos.

Bourdieu (1986) diferencia tipos de capital. Os dois principais são os capitais econômico e cultural. O capital econômico diz respeito à posse de dinheiro ou riqueza material, que permite a aquisição direta de bens e serviços. O capital cultural corresponde ao conhecimento culturalmente valorizado e, frequentemente, certificado. O capital cultural dá acesso a condições sociais que acabam por permitir um trabalho de conversão em capital econômico, quando por exemplo se fala de empregos que exigem alta qualificação, restritos àqueles que atingem graus de estudo elevados, e aos quais é concedida alta remuneração.

Baseando-me na contribuição de Bourdieu, avalio as combinações de capital econômico e cultural em termos de estratos de renda e escolarização, propondo uma classificação que permite apreender posições na sociedade em termos de possibilidades de ação sobre ela, e portanto graus de controle sobre a própria existência. A posição com níveis mais elevados de capital econômico e cultural — por exemplo, alguém com alta renda mensal e ensino superior completo- consegue desfrutar do que é produzido pela sociedade muito mais do que uma posição desfavorável — baixa renda e pouco estudo. Além disso, a consideração de coordenadas divergentes ou posições mistas - alto capital econômico e baixo capital cultural e vice-versa, ou mesmo níveis elevados de um e intermediários de outro viabiliza identificar trajetórias mais complexas, por vezes contraditórias.

\section{Valores e posições sociais}

Parto do pressuposto de que as experiências de juventude e de socialização por parte de familiares, professores e amigos, bem como condições gerais de vida, como moradia, consumo, escolas e instituições frequentadas por pessoas com graus variados de capital econômico e cultural são muito contrastantes. Suas necessidades imediatas e de longo prazo, bem como suas expectativas, podem ser bastante diferentes, refletindo modos distintos de existência, o que torna a investigação comparativa de prioridades de valores em termos de posição social pertinente. 
Godoy e Oliveira-Monteiro (2015) realizaram um estudo com resultados de prioridades valorativas de estudantes do ensino médio de seis escolas da Baixada Santista, no Estado de São Paulo. As autoras compararam os escores de estudantes que frequentavam escolas públicas e privadas com perfil socioeconômico diferente: considerando os estratos econômicos baseados em consumo, 58\% dos estudantes das escolas públicas era das classes A ou B, contra $92 \%$ nas escolas privadas. Portanto, alguns aspetos do estudo aproximam-se de uma investigação comparativa de posições sociais. De modo geral, as subfunções com maiores escores de importância foram existência e suprapessoal, similar aos resultados de Medeiros et al. (2012) com uma amostra geral e Gouveia et al. (2015a) com universitários. Os alunos de escolas públicas deram mais importância que os de escolas particulares aos valores das subfunções existência, normativa, realização e suprapessoal. Já os alunos das escolas particulares superaram os da pública na importância dada aos valores de experimentação.

Explicações possíveis para essas diferenças estão nos desafios e necessidades mais salientes nos contextos familiares e socioeconômicos dos participantes. Ainda que as amostras dos dois tipos de escola de Godoy e Oliveira-Monteiro (2015) não impliquem um contraste radical de classes sociais - ambas são formadas predominantemente pelas classes A e B-, a situação dos participantes das escolas particulares é mais favorável. Desse modo, são os alunos de escolas públicas que tem de se preocupar mais com sua estabilidade biológica e psicológica no presente e futuro, e com metas de sustento financeiro, o que explicaria escores mais altos de valores de existência e realização. Por outro lado, suas famílias, com condições econômicas inferiores, provavelmente têm graus inferiores de escolaridade. Nesse sentido, uma pesquisa de Almeida (2012), com dados da Pesquisa Social Brasileira de 2002, indicou que menos anos de estudo estavam associados a opiniões mais conservadoras em termos comportamentais, a um entendimento fatalista da vida, e a pontos de vista autoritários. Esse tipo de pensamento hierárquico pode explicar a maior priorização de valores normativos no estudo de Godoy e Oliveira-Monteiro (2015). Já os estudantes com melhores condições das escolas particulares podem ter menos privações e dedicar mais seus interesses a novas experiências e sensações típicas da adolescência.

Dentro dessa linha de pesquisa, o presente estudo teve por objetivo caracterizar a importância dos valores pessoais para estudantes adolescentes de Uberlândia, Minas Gerais, levando em conta sua posição social. Desse modo, torna-se possível avaliar mais precisamente a relação entre posição social (capitais econômico e cultural) e prioridades valorativas.

\section{Método}

O estudo relatado é parte da Pesquisa de Percepções Sociais de Estudantes Uberlandenses com coleta de dados em 2013 (Perseu-2013). A pesquisa foi um levantamento de dados (survey) caracterizado pelo questionamento de uma amostra acerca de suas opiniões, de modo a comparar as respostas de grupos de participantes. No presente caso, os grupos avaliados correspondem às posições sociais de estudantes em termos de grau de escolaridade materna e classe de renda familiar, e as questões de interesse são avaliações da importância dos valores básicos, a partir de uma adaptação do Questionário de Valores Básicos (QVB). A pesquisa teve finalidade exploratória e descritiva.

\section{Participantes}

Os participantes foram adolescentes estudantes da segunda série do ensino médio de duas escolas públicas e uma privada de Uberlândia, Minas Gerais, que constituíram uma amostra de conveniência, conforme concordância das escolas. A amostra teve 736 respondentes considerados, com equilíbrio quanto ao sexo: 51,5\% eram meninas. A média de idade foi de 16 anos ( $\mathrm{DP}=0,87$ anos); 90,1\% dos participantes tinham idade entre 15 e 17 anos. 


\section{Instrumento}

A Perseu-2013 fez uso de um questionário de opinião, solicitando informações sobre valores básicos — tema deste trabalho-; valores societais, isto é, avaliações sobre a importância de alguns valores para construir uma sociedade ideal, conforme os princípios teóricos de Pereira, Camino e Costa (2005); opiniões sobre sucesso no trabalho e percepções sobre justiça, especialmente se as pessoas consideram o destino dos outros justo ou injusto. Além disso, o questionário solicitava informações sociodemográficas, com destaque para sexo, idade, escolaridade do pai e mãe, e posse familiar de itens de consumo e acesso a serviços: geladeira, automóvel, serviço de empregado doméstico, máquina de lavar e assim por diante.

As avaliações sobre valores consistiram numa adaptação do Questionário de Valores Básicos (QVB) (Gouveia, Milfont, Fischer, \& Santos, 2008), descrita em Wachelke e Rodrigues (2015). A adaptação apresenta os 18 valores do QVB, que se agrupam em seis subfunções, já listadas na seção da introdução deste trabalho a respeito dos valores pessoais. O nome de cada valor foi acompanhado de uma descrição de seu significado, que em alguns casos foi ligeiramente modificada em relação ao QVB original para facilitar a compreensão de palavras menos usuais por estudantes secundaristas. Os respondentes avaliavam a importância de cada valor como um princípio-guia em suas vidas, podendo escolher dentre três respostas: pouco importante, mais ou menos importante, e muito importante.

\section{Procedimentos}

O Comitê de Ética em Pesquisa da Universidade Federal de Uberlândia aprovou a Perseu-2013, parecer n. 379.510. Informei os pais e responsáveis dos estudantes das escolas parceiras a respeito do teor do estudo, por meio de Termo de Consentimento Livre e Esclarecido, que foi assinado e devolvido. A coleta de dados ocorreu em salas de aula das escolas no segundo semestre de 2013, durante o horário letivo. Os participantes tiveram 45 minutos para responder os questionários individualmente em situação coletiva.

No que diz respeito à análise de dados, primeiramente defini a variável de posição social por meio do cruzamento da escolaridade da mãe com a classe econômica familiar do estudante. Avaliei a escolaridade da mãe por ela mostrar-se mais relacionada à escolaridade atingida pelos filhos que a escolaridade paterna, conforme Buchmann (2002). Em um caso com dados omissos, esta foi substituída pela escolaridade do pai.

Agrupei as informações de escolaridade em duas categorias, Até Ensino Médio (F/M) —mães que nunca estudaram até as que cumpriram o equivalente ao ensino médio ou antigo segundo grau-, e Ensino Superior $(\mathrm{S})$ — mães que concluíram estudos universitários - . Essas modalidades tiveram frequências 404 e 332, respectivamente. Defini classes econômicas a partir de uma adaptação do Critério de Classificação Econômica Brasil de 2013, da Associação Brasileira de Empresas de Pesquisa (2013). Trata-se de uma classificação de famílias a partir da posse de itens de consumo e da escolaridade do chefe da família - considerei a escolaridade paterna - gerando uma pontuação que classifica a família do respondente em classes de renda. Os participantes da classe A (renda média familiar estimada pelo CCEB de R\$ 9.263) foram 247, houve 188 da B1 (renda média de R \$ 5.241), 190 da B2 (renda média de R \$ 2.654) e 111 da C (grupo formado pela agregação de C1, renda média $\mathrm{R} \$ 1.685$, e C2, renda média de $\mathrm{R} \$ 1.147)$.

Combinei as variáveis de escolaridade da mãe e renda familiar, obtendo oito posições sociais possíveis: A com nível superior (A.S): 194 participantes; A com máximo nível médio (A.F/M): 53; B1 com nível superior (B1.S): 95, B1 com máximo nível médio (B1.F/M): 93; B2 com nível superior (B2.S): 33, B2 com máximo nível médio (B2.F/M): 157, C com nível superior (C.S): 10, e $\mathrm{C}$ com máximo nível médio (C.F/M): 101. Devido à pequena quantidade de participantes na posição 
social C.S, excluí seus dados da análise. A amostra final considerando as posições sociais teve 726 respondentes.

Posteriormente, realizei análises descritivas de frequência a partir das proporções de cada modalidade de resposta para cada valor, apresentando-as na forma de gráficos de barras empilhadas. Finalmente, realizei uma análise de correspondências a partir de uma tabela de contingências posição social $\times$ importância dos valores, em que as colunas referentes às respostas de importância de cada valor foram concatenadas, de modo a sintetizar as principais associações entre posições sociais e respostas de importância aos valores básicos.

A análise de correspondências é uma técnica multivariada de visualização de dados para representação de tabelas de contingência. Esse tipo de tabela consiste na tabulação cruzada das modalidades de variáveis nominais. A análise permite avaliar relações entre as linhas e colunas da tabela, por meio da decomposição da variação (inércia) dos dados da tabela em relação ao perfil médio em dimensões independentes, também chamadas eixos ou fatores. Os perfis relativos das linhas e colunas, isto é, os valores das linhas e colunas da tabela em relação às suas margens (totais), são representados como pontos num mapa, cuja qualidade diz respeito à proporção de inércia explicada por ele; comumente, isso implica a soma das inércias dos dois eixos (horizontal e vertical) que constituem o plano por eles formado. Por sua vez, as margens da tabela atuam ponderando a importância de cada ponto. As distâncias entre os perfis são definidas como distâncias qui quadrado, basicamente distâncias euclidianas ponderadas (Greenacre, 2007). No mapa, a origem ou centroide diz respeito ao perfil médio, a margem da tabela, e corresponde à localização em que não haveria diferença entre perfis. As distâncias entre pontos do mesmo tipo, isto é, distâncias entre linhas ou distâncias entre colunas — mas não entre linhas e colunas - relacionam-se à semelhança dos perfis; quanto mais os pontos de um mesmo tipo estão próximos, mais próximas são as proporções a eles associadas. Quando se encontram distantes, os perfis são mais contrastantes, com pontos espalhados (Alberti, 2013).

A concatenação de tabelas de contingência que envolvam os mesmos indivíduos permite avaliar as relações entre as posições sociais e cada valor, o que não leva em conta as interações entre os valores, mas sintetiza os resultados de todos num único mapa (Greenacre, 2007). Assim, submeti a matriz empilhada ou concatenada 7 (posições sociais) $\times 36$ (2 modalidades de importância de resposta aos valores $\times 18$ valores) à análise. As respostas de baixa e média importância foram agrupadas, pois tinham efetivos muito baixos em alguns casos e também me interessava mais contrastar as respostas de alta importância com as demais, haja vista a alta desejabilidade social do tema.

Realizei as análises no programa $R$ (R Core Team, 2016), com auxílio do pacote FactoMineR (Lê, Josse \& Husson, 2008). Os gráficos foram gerados com os pacotes ggplot2 (Wickham, 2009) e factoextra (Kassambara \& Mundt, 2016).

\section{Resultados}

A Figura 1 apresenta resultados de proporções referentes aos 18 valores básicos. Considerei as modalidades de resposta pouco importante, mais ou menos importante e muito importante respectivamente como importância baixa, média e alta. Cada linha da Figura 1 apresenta os valores de uma subfunção, de cima para baixo: existência, realização, normativa, suprapessoal, experimentação e interativa.

A inércia $\left(\phi^{2}\right)$ diz respeito à estatística qui quadrado de cada tabela posição $\times$ respostas dividida pelo tamanho da amostra. A comparação das inércias permite uma avaliação de quais valores tiveram maior ou menor variação entre as posições sociais; quanto maior a inércia, maior a variação. 
Figura 1. Proporções de Importância dos Valores Básicos por Posição Social

Saúde $\left(\phi^{2}=0.02\right)$
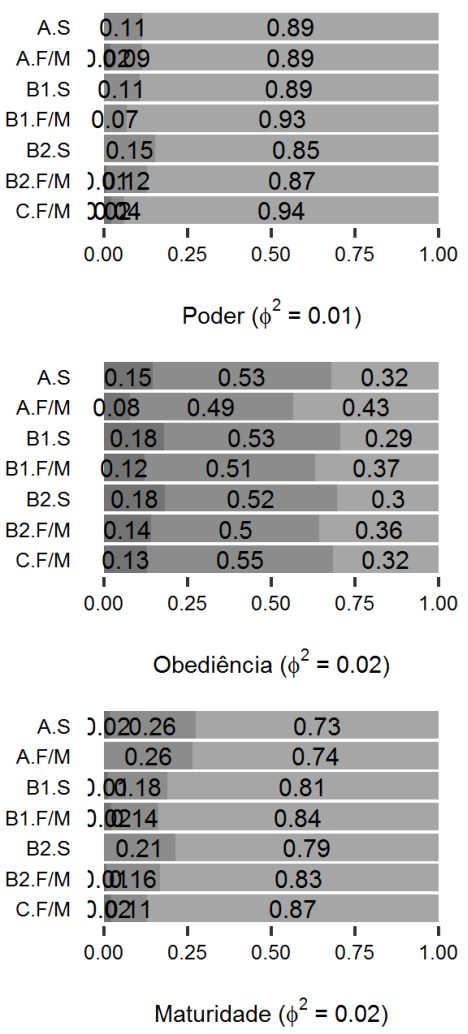

\begin{tabular}{|c|c|c|c|c|c|}
\hline A.S & 0.0 .09 & & 0.9 & & \\
\hline A.F/M & 0.06 & & 0.94 & & \\
\hline B1.S & 0.06 & & 0.94 & & \\
\hline B1.F/M & J.021 & & 0.88 & & \\
\hline B2.S & 0.03 & & 0.97 & & \\
\hline B2.F/M & 0.04 & & 0.96 & & \\
\hline C.F/M & 0.07 & & 0.93 & & \\
\hline & 0.00 & $\begin{array}{c}\mathbf{c}^{\prime} \\
\end{array}$ & $\begin{array}{c}1 \\
0.50\end{array}$ & 0.75 & $\begin{array}{c}1 \\
1.00\end{array}$ \\
\hline
\end{tabular}

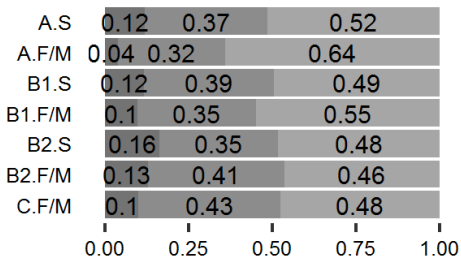

Afetividade $\left(\phi^{2}=0.03\right)$

\begin{tabular}{|c|c|c|}
\hline A.S & 0.060 .25 & 0.69 \\
\hline A.F/M & J.02 0.32 & 0.66 \\
\hline B1.S & 0.050 .25 & 0.69 \\
\hline B1.F/M & $0,070.2$ & 0.74 \\
\hline B2.S & 0.090 .18 & 0.73 \\
\hline B2.F/M & 0.06 .15 & 0.8 \\
\hline C.F/M & 0.0312 & 0.85 \\
\hline & $\begin{array}{ll}1 & 1 \\
0.00 & 0.25\end{array}$ & 0.50 \\
\hline
\end{tabular}

Importância
Sobrevivência $\left(\phi^{2}=0.03\right)$
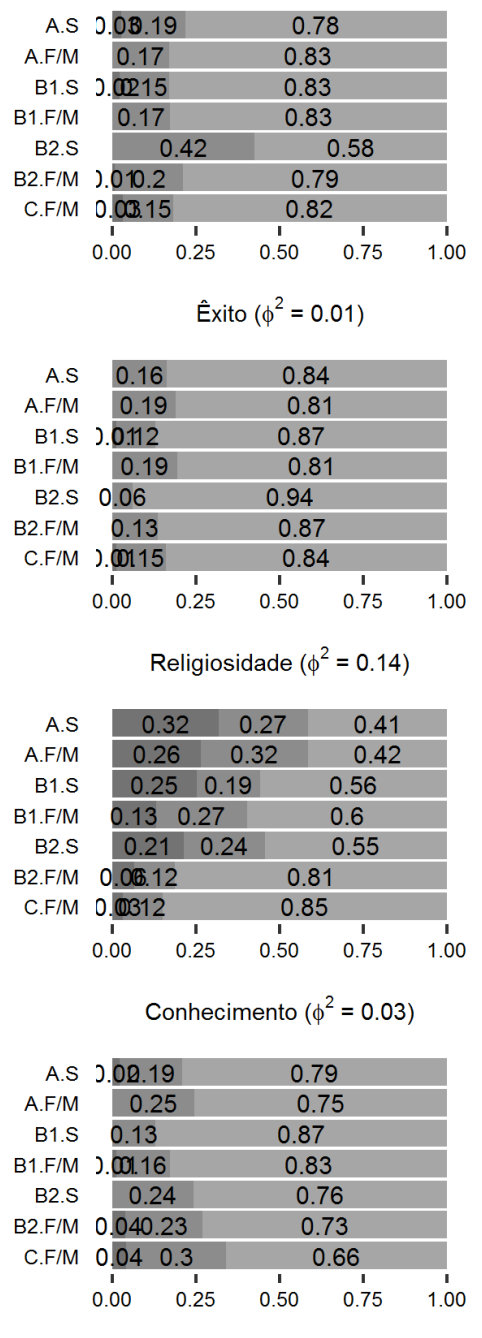

Prazer $\left(\phi^{2}=0.01\right)$
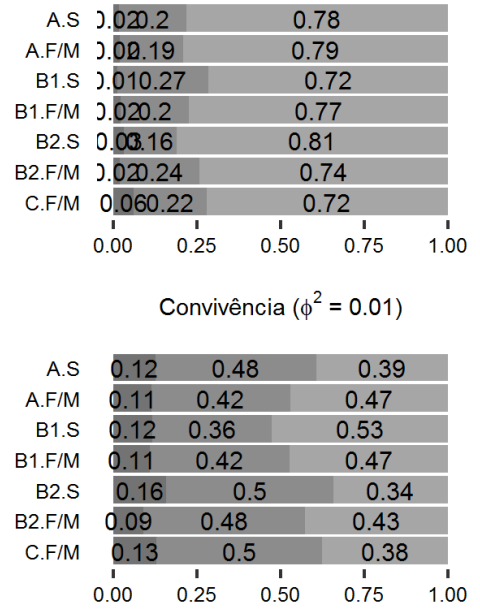

Baixa Média
Estab. Pessoal $\left(\phi^{2}=0.03\right)$
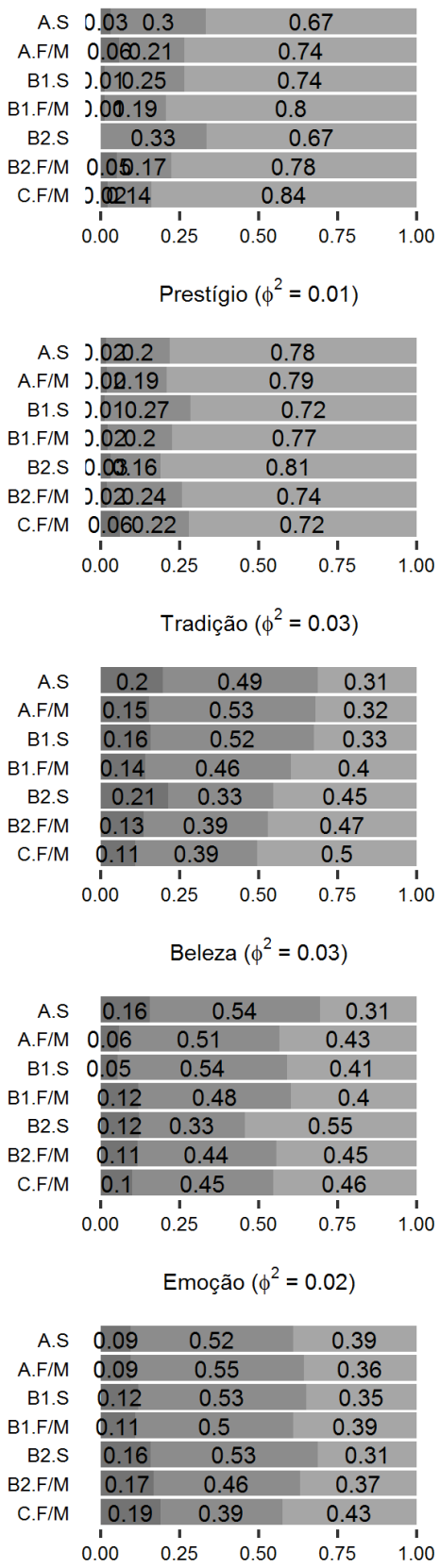

Apoio Social $\left(\phi^{2}=0.02\right)$

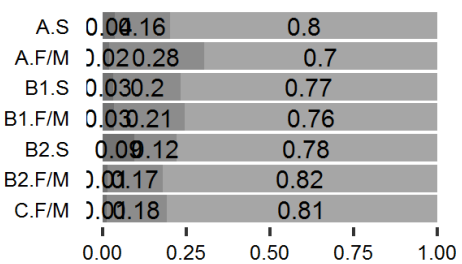

Alta 
Uma inspeção da Figura 1 permite observar que as respostas de baixa importância aos valores têm baixas proporções. Predominam respostas de média e alta importância, até mesmo porque os valores tendem a ser considerados desejáveis socialmente (Gouveia, 2003), isto é, percebidos positivamente. Desse modo, concentro a interpretação das frequências nas proporções de respostas de alta importância.

Há três padrões identificáveis. Um primeiro diz respeito aos consensos e tendências majoritárias na amostra: valores em que predominaram as respostas de alta importância dentre todas ou quase todas as posições sociais. Os valores consensuais, com proporções de alta importância superiores a 0,85, foram saúde (subfunção existência) e maturidade (suprapessoal), e os valores majoritários, com alta importância superior a dois terços, foram sobrevivência (apesar de B2.S ter proporção um pouco inferior), estabilidade pessoal (existência); êxito, prestígio (realização); obediência (normativa); conhecimento (suprapessoal); prazer (experimentação), e apoio social (interacional).

Um segundo padrão, por sua vez, diz respeito a valores em que as respostas de alta importância foram minoria dentre todas ou quase todas a posições sociais. São valores que poderemos chamar de valores com adesão minoritária, que foram os casos de poder, convivência e emoção.

Finalmente, um terceiro padrão corresponde a variações de priorização entre as posições sociais, com possibilidades diferentes de distribuição. As maiores variações dizem respeito ao valor normativo religiosidade. Houve tendência de maior importância para a religiosidade com a redução de volume de capital. As posições sociais com mães com escolaridade até no máximo ensino médio e das duas classes econômicas inferiores apresentam proporções de alta importância maiores que 0,80 . Em contraste, as duas posições com classe econômica A tem proporções na casa dos 0,40 , e há um bloco intermediário entre 0,55 e $0,60 \mathrm{com}$ as demais posições. Também no caso do valor normativo tradição, a importância aumenta conforme se reduzem os volumes dos tipos de capital, formando um gradiente que parte de 0,31 para a posição A.S e chega a 0,50 para C.F/M. Por fim, afetividade é um valor interacional com proporções majoritárias, mas também com tendência de aumento da adesão conforme se diminui o capital. Contudo, é importante ressaltar que as diferenças de avaliações de valores entre as posições sociais são na maior parte das vezes sutis, destacando-se a existência de opiniões semelhantes entre as combinações de renda e escolaridade. Os comentários sobre associações entre posição social e a adesão aos valores devem ser interpretados dentro desse cenário.

Para realizar a análise de correspondências na matriz concatenando as tabelas de contingências posições sociais $\times$ respostas de importância aos valores, eliminei todos os participantes do banco de dados que não tivessem dados sobre essas informações, o que resultou num banco com 707 participantes. A Figura 2 apresenta o mapa da análise, com duas dimensões cobrindo pouco mais de $80 \%$ da variação (inércia) total. Seguindo recomendações de de Le Roux e Rouanet (2004), as modalidades de respostas aos valores e posições sociais representadas, que guiaram a interpretação, correspondem àquelas que contribuem mais que a média para cada fator, ou que pelo menos tiveram contribuições relativas — percentuais da inércia de cada variável explicadas pela dimensãoelevadas; optei pelo valor de 0,50 , o que quer dizer que o fator explica pelo menos metade da inércia da variável. 
Figura 2. Mapa das Variáveis com Contribuiçôes Absolutas e Relativas Superiores à Média na Análise de Correspondências Referente à Tabela Posições Sociais $\times$ Respostas de Importância aos Valores Básicos ${ }^{1}$

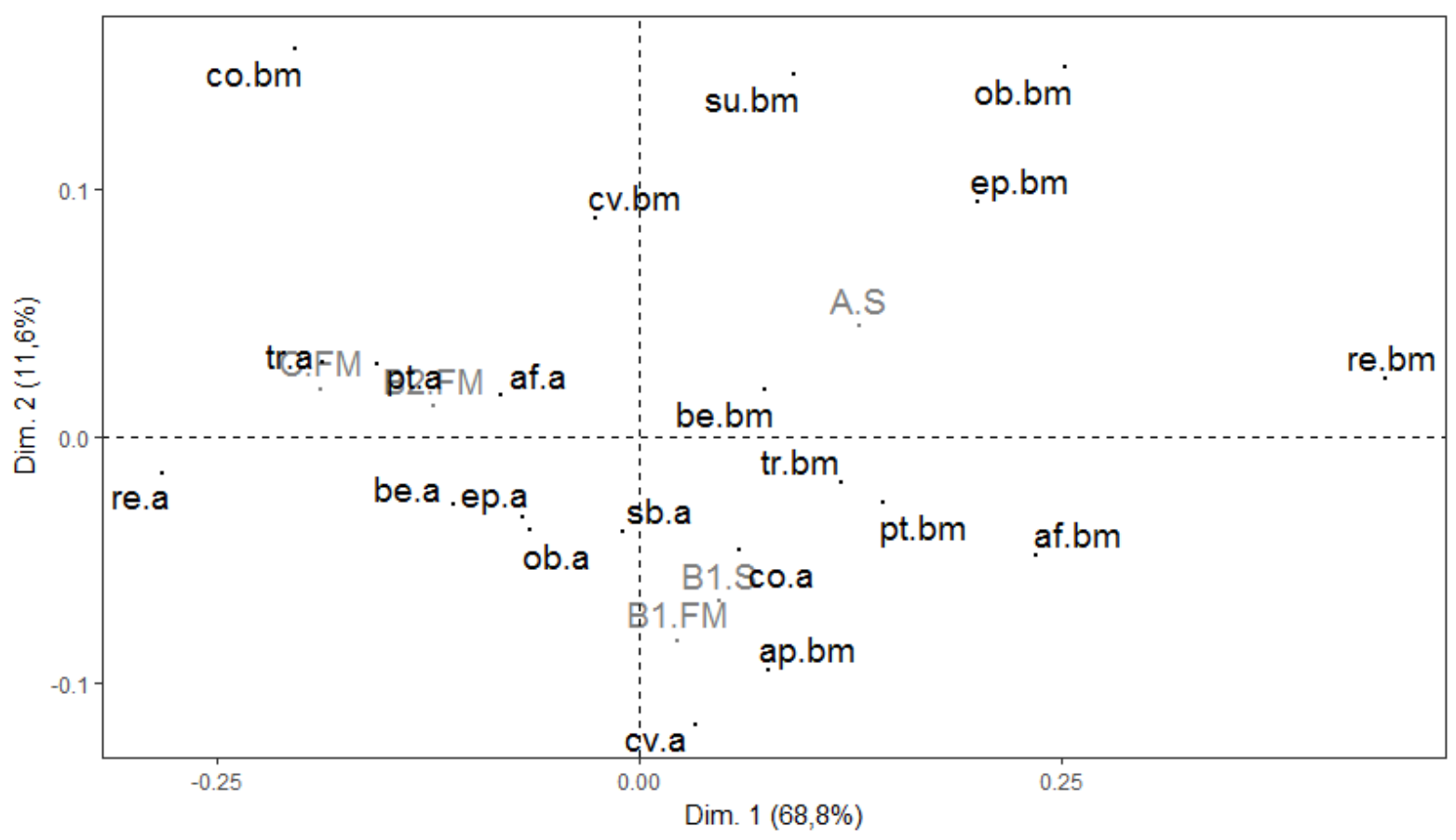

A primeira dimensão, representada no plano horizontal, traduz as principais associações da análise, e tem grande diferença de inércia em relação aos demais fatores: explica $68,8 \%$ da inércia total. O contraste contido na dimensão é entre a posição social de estudantes de classe econômica A e mãe com escolaridade de nível superior e estudantes das duas classes econômicas mais desfavorecidas (B2 e C) e mães com escolaridade no máximo até nível médio, com localização próxima entre si. Ou seja, são as associações que expressam as diferenças entre os extremos da esfera social. Em relação à associação das respostas aos valores básicos com o fator, quase metade da inércia é explicada pelo valor religiosidade. Os outros dois valores da subfunção normativa, tradição e obediência, também contribuem para a dimensão ou então estão pelo menos bem representados nela. Os valores normativos contribuem com $64,6 \%$ da inércia da dimensão, ressaltando que esse é o principal contraste. As respostas de baixa ou média importância dos valores normativos associam-se às coordenadas positivas da dimensão, isto é, a uma maior proporção que a média da amostra para os participantes da posição A.S, enquanto que o lado oposto do fator, típico das posições B2.F/M e C.F/M, são marcadas pela alta importância dada aos aspectos normativos, como confirma a Figura 1. Completando a dimensão, a extremidade do eixo típica das posições B2.F/M e C.F/M associa-se à alta importância aos valores afetividade, prestígio, beleza e estabilidade e baixa relevância ao conhecimento, enquanto o polo em que está A.S teve maior associação com as respostas opostas.

A segunda dimensão, vertical, expressa diferenças pequenas de proporções. $O$ fator marca as diferenças entre as posições A.S e as posições com renda B1 das duas modalidades de escolaridade consideradas. A posição A.S tende a estar associada a proporções um pouco maiores de importância inferior ao conhecimento, saúde, obediência, estabilidade, sobrevivência e convivência. As repostas

\footnotetext{
Abreviações para os valores: sx - sexualidade; ex - êxito; ap - apoio social; co - conhecimento; em - emoção; po - poder; af - afetividade; re - religiosidade; su - saúde; pr - prazer; pt - prestígio; ob - obediência; ep - estabilidade pessoal; cv - convivência; be - beleza; tr - tradição; sb sobrevivência: $\mathrm{mt}$ - Maturidade Abreviacões para as respostas aos valores: bm - baixa ou média importância: a - alta importância
} 
dos participantes das posições sociais com classe de renda B1 deram importância inferior ao apoio social, e elevada à convivência e sobrevivência e conhecimento. Isto é, temos os participantes da A.S dando baixa prioridade a valores de existência e alguns suprapessoais, bem como a necessidade de se obedecer regras, e os participantes do estrato de renda B1 voltados para a participação e convívio em grupos e dando menos importância para a necessidade de ajuda de outros, e valorizando a busca de conhecimento sobre o mundo.

\section{Discussão}

A amostra de estudantes do segundo médio de Uberlândia apresentou resultados que reproduzem algumas das principais tendências de estudos anteriores realizados com estudantes secundaristas e universitários. Assim como nas pesquisas de Medeiros et al. (2012), Gouveia et al. (2015a) e especialmente Godoy e Oliveira-Monteiro (2015), houve alta priorização geral de valores com orientação central, relativos às subfunções existência e suprapessoal. Porém, a avaliação dos valores separadamente permitiu identificar uma exceção: o valor beleza, que no QVB diz respeito à apreciação da arte, música e literatura, teve proporções baixas de respostas de alta importância. Talvez o enunciado correspondente a esse valor induza os participantes a associá-lo com manifestações artísticas clássicas, menos populares entre adolescentes. Uma pesquisa de Pimentel, Gouveia e Pessoa (2007) com estudantes do ensino médio de João Pessoa - PB apontou que o estilo musical clássico tinha um dos escores mais baixos de preferência. Possivelmente isso se aplica também a outros tipos de manifestação artística.

Comparando grupos etários, Gouveia et al. (2015b) observaram valores normativos mais altos na adolescência, mas no presente estudo somente o valor obediência teve avaliações de alta importância elevadas entre todas as posições sociais. A priorização desse valor reflete, provavelmente, a influência da hierarquia familiar e inculcação da disciplina escolar, instâncias de socialização primordiais especialmente antes do início da idade adulta.

Em contraste, os demais valores normativos — religiosidade e tradição — têm ampla variação entre as posições sociais e constituíram as principais diferenças de proporções dentre os valores investigados. Assim como os resultados de Godoy e Oliveira-Monteiro (2015) para a subfunção normativa, os participantes das posições sociais desfavorecidas tiveram maiores índices de alta importância para o valor religiosidade. No presente estudo, as diferenças foram mais pronunciadas, possivelmente pelos maiores contrastes sociais na amostra. As religiões frequentemente se mostram associadas a níveis diferentes de religiosidade e prática religiosa. Coutinho (2011) apresentou dados de estudantes de escolas estaduais da região de Belo Horizonte-MG, matriculados majoritariamente na segunda série do ensino médio, e observou que $36 \%$ dos católicos se diziam praticantes, contra mais de $70 \%$ dos evangélicos. Os praticantes de todas as religiões também tiveram maiores proporções de declaração de alta religiosidade, em comparação com os respondentes de prática esporádica. Na amostra deste estudo, a composição religiosa das posições sociais foi diferente. Uma análise posterior dos dados indica que para a posição A.S, 44,8\% declaram-se católicos, 15,4\% ateus e 11,9\% evangélicos. Para os participantes da posição A.F/M, essas proporções são de 39,6\%, 9,4\% e 17\% respectivamente. Em contraste, para C.F/M, foram 35,6\%, 1\% e 43,6\%, e para B2.F/M, 37,6\%, 2,5\% e 42,7\%. Portanto, mesmo sem dados específicos sobre a religiosidade, é plausível estimar que esse perfil diferenciado das religiões nas posições sociais explique a maior importância dada ao valor religiosidade na parte de baixo da escala da posição social.

A pesquisa de Almeida (2012) apontou que brasileiros com menos escolaridade tinham pontos de vista tradicionais. A priorização da religiosidade por participantes com baixa escolaridade e renda familiar pode ser em parte explicada desse modo, ainda ligado ao pensamento de instituições como as igrejas. Além disso, a religiosidade, especialmente ligada à fé cristã, pode representar uma estratégia para lidar com os problemas da vida ou encontrar motivação para as pessoas de posições inferiores, seja confortando-as frente à promessa de felicidade na vida após a morte para compensar a infelicidade 
terrena, para os que se encontram em condições piores; ou dando esperanças e perspectivas de ascensão social ao promover noções ideológicas como a meritocracia e o individualismo, bem como uma rede coletiva de suporte. A esse respeito, ver Arenari e Torres (2012).

Dentre os vários sentidos de ideologia, um dos mais difundidos é o de conhecimento que contribui para a manutenção de relações de poder, o que ocorre de modo mais eficiente quando é oculto ou irreconhecível (Žižek, 1996a). Segundo esse entendimento, a religião pode constituir uma ideologia quando inibe questionamentos sobre a distribuição desigual dos produtos do trabalho social, prevenindo mudanças, como quando se estabelece que a explicação última da sociedade está em fenômenos que ultrapassam o observável —Deus, por exemplo - ou promovem percepções de fatalismo ou conformismo - como quando se fala na vida após a morte ou na necessidade de aceitar o que Deus determina, dentre outras expectativas. Mesmo o individualismo ou meritocracia associado com algumas crenças religiosas, isto é, a busca por soluções individuais para ascensão social, e a percepção de que o sucesso obtido significa algum tipo de graça ou eleição divina, operam como ideologias na medida em que desviam as preocupações das relações sociais, transferindo-as para a vida pessoal e sua relação com a esfera mística. Se é assim, os resultados do presente estudo podem indicar que adolescentes em posições sociais menos favorecidas abraçam mais esse caminho para entender e estruturar suas práticas, o que pode ter efeito conservador nas forças sociais por desestimular a mudança coletiva.

Os valores êxito e prestígio, da subfunção realização, tiveram altas proporções de importância, o que faz sentido já que os adolescentes buscam definir sua trajetória profissional futura e almejar a independência. Essa subfunção tem valores maiores nessa fase da vida, conforme Gouveia et al. (2015b). Porém, o valor poder teve uma predominância de avaliações de importância intermediária, diferente dos demais. Uma possibilidade para explicar esse resultado está na tendência dos brasileiros, quando comparados com outras culturas, se mostrarem mais coletivistas que individualistas, isto é, mais orientados para a interdependência com outras pessoas e relações comunitárias (Gouveia \& Clemente, 2000; Hofstede, Hofstede, \& Minkov, 2010). Talvez a menor importância dada ao valor poder possa ser explicada por uma rejeição relativa ou desaprovação da hierarquização e primazia individuais. Interpretações antropológicas defendem que o brasileiro percebe expressões explícitas de poder e hierarquia negativamente (Barbosa, 2005; DaMatta, 1997), mas paradoxalmente a hierarquia e a desigualdade são aceitas na cultura nacional (Hofstede et al., 2010).

Um aspecto inesperado dos resultados consiste no comportamento diferenciado de valores de uma mesma subfunção. As medidas da teoria funcionalista de valores ocasionalmente apresentam índices de fidedignidade intermediários ou baixos (Gouveia, 2003; Gouveia, Milfont \& Guerra, 2014), o que é justificado por Gouveia, Santos e Milfont (2009) pelo alto consenso nas amostras e baixa quantidade de indicadores por dimensão. No entanto, o presente estudo não teve consensos generalizados, com boa dose de variações entre posições sociais, e mostrou resultados que podem ser interpretados por uma lógica social coerente. É necessário, contudo, fazer a ressalva de que os resultados aqui mostrados e os de outros estudos não são diretamente comparáveis em termos de opções de resposta, mas outro estudo com a mesma amostra (Wachelke \& Rodrigues, 2015) em que os autores optaram por tratar as respostas como escalas Likert de 3 pontos houve indicadores de fidedignidade baixos. Em todo caso, dependendo dos objetivos de pesquisa, pode ser relevante desmembrar os escores do QVB em termos de valores isolados.

Os resultados do trabalho sugerem a pertinência de realizar estudos relacionando valores básicos e as posições sociais ocupadas pelas pessoas. As regularidades encontradas sugerem que as condições comuns de existência refletidas nas posições sociais contribuem para a convergência de objetivos pessoais, indicando um efeito social na priorização de valores. Nos termos de Bourdieu (1977), essas disposições ligadas às posições sociais são os habitus, esquemas cognitivos e afetivos inculcados e estruturados a partir das experiências ligadas às posições na sociedade, e que por sua vez estruturam práticas compatíveis, contribuindo para a reprodução social. A modulação social das priorizações 
valorativas foi mais evidente nos valores religiosidade e tradição, ligados a aspectos normativos, apontando diferenças nas vivências e estratégias nos opostos do espectro social.

Por outro lado, há ampla semelhança em termos de priorização de valores centrais, o que corrobora um resultado geral de diversos estudos apresentados, e também de realização, comumente encontrados na faixa etária investigada. Contudo, não entendo que isso reflita meramente uma tendência de ciclo de vida, mas antes a inserção em condições de existência da adolescência no capitalismo contemporâneo, acarretando a necessidade de definição da situação pessoal nas forças de trabalho, seja durante ou logo após a vida escolar.

Frente à alta desejabilidade social dos valores e aos padrões comuns de priorização, uma linha de pesquisa que pode contribuir para dar sequência ao estudo apresentado aqui envolve o estudo conjunto de valores e práticas sociais a eles associados. Em termos da manutenção da ideologia e da hegemonia, autores como Žižek (1996b) defendem que as práticas são essenciais na manutenção dos sistemas sociais, promovendo a ideologia por mais que as pessoas não pensem a respeito delas ou mesmo tenham críticas. Cabe verificar se à semelhança nas avaliações dos valores corresponde equivalente proximidade no nível de práticas, ou se objetivos semelhantes estão acompanhados de práticas contrastantes —e se esse for o caso, buscar entender o papel cumprido pela priorização de valores nesse tipo de situação.

Finalmente, referindo-me a uma limitação do estudo, é importante enfatizar que se trata de pesquisa exploratória realizada junto a uma amostra de conveniência. Por esse motivo, optei por empregar análises estatísticas descritivas, já que as amostras de conveniência tornam o uso de estatísticas inferenciais problemático, pois estas pressupõem amostragem probabilística para produzir estatísticas confiáveis (ver Berk \& Freedman, 2003). O tratamento descritivo empregado para analisar os dados é coerente com a finalidade de compreensão do contexto particular de pesquisa, sem vistas à generalização para uma população. Portanto, é necessário restringir as conclusões à amostra do estudo, e replicações ou estudos semelhantes poderão verificar diferenças ou aspectos robustos dos resultados aqui relatados.

\section{Referências}

Alberti, G. (2013). An R script to facilitate correspondence analysis. A guide to the use and the interpretation of results from an archaelogical perspective. Archeologia e Calcolatori, 24, 25-53.

Almeida, A. C. (2012). A cabeça do brasileiro. Rio de Janeiro: Record.

Arenari, B., \& Torres, R. (2012). Os batalhadores e o pentecostalismo: um encontro entre classe e religião. In J. Souza (Ed.), Os batalhadores brasileiros. Nova classe média ou nova classe trabalhadora?, (pp. 311-348). Belo Horizonte: UFMG.

Associação Brasileira de Empresas de Pesquisa. (2013). Critério de Classificação Econômica Brasil. Alterações na aplicação do Critério Brasil, válidas a partir de 01/01/2013. Disponível em: http://www.abep.org.

Barbosa. L. (2005). Jeitinho brasileiro. A arte de ser mais igual que os outros. Rio de Janeiro: Campus.

Berk, R. A., \& Freedman, D. A. (2003). Statistical assumptions as empirical commitments. In T. G. Bloomberg, S. Cohen (Eds.), Law, punishment, and social control: Essays in honor of Sheldon Messinger, (pp. 235-254). Nova Iorque: Aldine de Gruyter. doi:10.1017/cbo9780511815874.004

Bourdieu, P. (1977). Outline of a theory of practice. Cambridge: Cambridge University Press. doi:10.1017/CBO9780511812507

Bourdieu, P. (1986). The forms of capital. In J. Richardson (Org.), Handbook of theory and research for the sociology of education, (pp. 241-258). Westport: Greenwood.

Bourdieu, P. (1989). La noblesse d'État: grandes écoles et esprit de corps. Paris: Minuit.

Buchmann, C. (2002). Measuring family background in international studies of education: Conceptual issues and methodological challenges. In A. Porter, \& A. Gamoran (Orgs.), Methodological 
advances in cross-national surveys of educational achievement, (pp. 150-197). Washington: National Academy Press.

Coutinho, R. Z. (2011). A carne é fraca: religião, religiosidade e iniciação sexual entre estudantes do ensino médio na Região Metropolitana de Belo Horizonte, 2008. (Dissertação de mestrado). Universidade Federal de Minas Gerais, Belo Horizonte, Brasil. Recuperado de: http://bdtd.ibict.br/vufind/Record/UFMG_f649f9570c585ef6389fcb4d41b75e52

DaMatta, R. (1997). Carnavais, malandros e heróis. Para uma sociologia do dilema brasileiro. Rio de Janeiro: Rocco.

Godoy, P. B. G., \& Oliveira-Monteiro, N. R. (2015). Estudo sobre valores em adolescentes. Psico, 46(3), 400-408. doi:10.15448/1980-8623.2015.3.19426

Gouveia, V. V. (2003). A natureza motivacional dos valores humanos: evidências acerca de uma nova tipologia. Estudos de Psicologia (Natal), 8(3), 431-443. doi:10.1590/s1413-294x2003000300010

Gouveia, V. V. (2013). Teoria funcionalista dos valores humanos. Fundamentos, aplicações e perspectivas. São Paulo: Casa do Psicólogo.

Gouveia, V. V., \& Clemente, M. (2000). O individualismo-coletivismo no Brasil e na Espanha: correlatos sócio-demográficos. Estudos de Psicologia (Natal), 5(2), 317-346. doi:10.1590/s1413294x2000000200003

Gouveia, V. V., Fonsêca, P. N., Milfont, T. L., \& Fischer, R. (2011). Valores humanos: contribuições e perspectivas teóricas. In C. V. Torres, \& E. R. Neiva (Eds.), Psicologia social: principais temas e vertentes, (pp. 298-313). Porto Alegre: Artes Médicas.

Gouveia, V. V., Milfont, T. L., Fischer, R., \& Coelho, J. A. P. M. (2009). Teoria funcionalista dos valores humanos: aplicações para organizações. Revista de Administração Mackenzie, 10(3), 3459. doi:10.1590/s1678-69712009000300004

Gouveia, V. V., Milfont, T. L., Fischer, R., \& Santos, W. S. (2008). Teoria funcionalista dos valores humanos. In M. L. M. Teixeira (Ed.), Valores humanos e gestão: novas perspectivas, (pp. 47-80). São Paulo: Senac.

Gouveia, V. V., Milfont, T. L., \& Guerra, V. M. (2014). Functional theory of human values: Testing its content and structure hypotheses. Personality and Individual Differences, 60, 41-47. doi:10.1016/j.paid.2013.12.012

Gouveia, V. V., Milfont, T. L., Vione, K. C., \& Santos, W. S. (2015a). Guiding actions and expressing needs: On the psychological functions of values. Psykhe, 24(2), 1-14. doi:10.7764/psykhe.24.2.884

Gouveia, V. V., Santos, W. S., \& Milfont, T. L. (2009). O uso da estatística na avaliação psicológica: comentários e considerações práticas. In C. S. Hutz (Ed.), Avanços e polêmicas em avaliação psicológica: em homenagem a Jurema Alcides Cunha, (pp. 127-155). São Paulo: Casa do Psicólogo.

Gouveia, V. V., Vione, K. C., Milfont, T. L., \& Fischer, R. (2015b). Patterns of value change during the life span: Some evidence from a functional approach to values. Personality and Social Psychology Bulletin, 41(9), 1276-1290. doi:10.1177/0146167215594189

Greenacre, M. (2007). Correspondence analysis in practice. Boca Ratón: Chapman \& Hall/CRC. doi:10.1201/9781420011234

Hofstede, G., Hofstede, G., \& Minkov, M. (2010). Cultures and organizations: Software of the mind. Nova Iorque: McGraw-Hill.

Inglehart, R. (1977). The silent revolution. Princeton: Princeton University Press.

Kassambara, A., \& Mundt, F. (2016). Factoextra: Extract and visualize the results of multivariate data analyses. Recuperado de: https://CRAN.R-project.org/package=factoextra

Le Roux, B., \& Rouanet, H. (2004). Geometric data analysis. From correspondence analysis to structured data analysis. Dordrecht: Kluwer. doi:10.1007/s00357-008-9007-7

Lê, S., Josse, J., \& Husson, F. (2008). FactoMineR: An R package for multivariate analysis. Journal of Statistical Software, 25(1), 1-18. doi:10.18637/jss.v025.i01 
Medeiros, E. D., Gouveia, V. V., Gusmão, E. E. S., Milfont, T. L., Fonseca, P. N., \& Aquino, T. A. A. (2012). Teoria funcionalista dos valores humanos: evidências de sua adequação no contexto paraibano. Revista de Administração Mackenzie, 13(3), 18-44. doi:10.1590/s167869712012000300003

Pereira, C., Camino, L., \& Costa, J. B. (2005). Um estudo sobre a integração dos níveis de análise dos sistemas de valores. Psicologia Reflexão e Crítica, 18(1), 16-25. doi:10.1590/S010279722005000100004

Pimentel, C. E., Gouveia, V. V., \& Pessoa, V. S. (2007). Escala de Preferência Musical: construção e comprovação de sua estrutura fatorial. Psico-USF, 12(2), 145-155. doi:10.1590/s141382712007000200003

R Core Team. (2016). $R$ : A language and environment for statistical computing. Recuperado de: https://www.R-project.org/.

Rokeach, M. (1973). The nature of human values. Nova Iorque: Free Press.

Schartz, S. H. (1992). Universals in the content and structure of values: Theoretical advances and empirical tests in 20 countries. In M. Zanna (Org.), Advances in experimental social psychology, 25, (pp. 1-65). San Diego: Academic Press.

Wachelke, J., \& Rodrigues, L. B. (2015). Estudo exploratório das relações entre valores básicos pessoais e psicossociais. Avaliação Psicológica, 14(3), 353-363.

Wickham, H. (2009). ggplot2: Elegant graphics for data analysis. Nova Iorque: Springer-Verlag. doi:10.1007/978-0-387-98141-3

Žižek, S. (1996a). O espectro da ideologia. In S. Žižek (Org.), Um mapa da ideologia, (pp. 7-38). Rio de Janeiro: Contraponto.

Žižek, S. (1996b). Como Marx inventou o sintoma? In S. Žižek (Org.), Um mapa da ideologia, (pp. 297-3831). Rio de Janeiro: Contraponto. 